officers and personnel managers who are seriously interested in the problems of performance and ageing. But it is not easy reading. In particular, the rather abstract chapter entitled, "On the Nature of Skill", although a masterpiece of condensation, may be unenlightening to those not conversant with contemporary psychology. (On the other hand it should be compulsory reading for third year psychology undergraduates.) In conclusion, it may be said that if someone wished to know what kind of sustained research had been done by experimental psychologists in this country since the war, no better examples could be found for them than the investigations reported here.

$$
\text { P. C. WASON }
$$

Een Onderzoek naar de asthmatische aard der Borstklachten van de Arbeiders in de Steenkolenmijnen (The Role of Asthmatic Predisposition in Coal Miners' Chest Complaints). By K. de Vries. (Pp. v + 124; 7 figures, 30 tables, 217 references. No price given.) Groningen: J. B. Wolters. 1958.

It has become increasingly obvious that in anthracosilicosis (coalworkers' pneumoconiosis) there is no close relationship between the severity of respiratory symptoms and the radiological changes in the lungs. The ingenious study described in this thesis was undertaken in order to investigate the hypothesis that miners' chest complaints are influenced by an asthmatic predisposition. An earlier survey of school children living in a mining community enabled the author to sample children with asthma and asthma-free controls, matched for age, sex, and place of residence. The male mining relatives of these two groups, 260 in the asthma and 104 in the control group, were then compared using the information given on the health record cards available for each man. (It should be noted that the meaning of the term "asthma" used in this work is wider than that now current in this country and includes what we should call chronic bronchitis and emphysema.)

The ages of the two groups were similar; but the occupational histories differed, the proportion of miners working underground being lower in the asthma group, a finding the author attributes to self-selection. The number of days of disability due to dyspnoea, wheszing, chest pain, and cough was higher in the asthma group than in the controls and also in those working underground compared with those on the surface. Periodic radiographs of the chest of every miner have been taken since 1949. No significant difference in the prevalence of anthraco-silicosis was observed between asthma and control groups, but among the young miners in the asthma group a significantly higher proportion of nonanthraco-silicotic lesions of the lower lung field, costophrenic sinus, and diaphragm was observed.

The author concludes that his findings support the hypothesis. He considers that they also indicate that miners' chest complaints are influenced by the underground milieu but not by the degree of anthraco-silicosis.

A detailed English summary and English subtitles to the tables and diagrams enable those who do not read Dutch to understand the greater part of this interesting monograph, which includes a very complete review of the literature.

I. T. T. Higgins
Occupational Allergy. Lectures held during a course on occupational allergy organized under the auspices of the European Academy of Allergy; Foreword by D. A. Williams. (Pp. xvi + 329; illustrated. Fl. 30.-.) Leiden, Holland: H. E. Stenfert Kroese N.V. 1958.

This book consists of 38 lectures given in May, 1958, under the auspices of the European Academy of Allergy. It is concerned with allergic reactions affecting the skin, eyes, and respiratory tract. The occupational aspects are broadly treated, since consideration is given both to those workers with pre-existing allergic manifestations and to the sensitization effects induced by working conditions; these are treated in some instances by industrial groups (bakers, pharmaceutical workers, printers, mine workers, cigar makers, cotton printers, and even the medical profession and its auxilaries), in others by discussion of offending substances (kapok, wool, turpentine, formaldehyde, wood dust, coffee, and pencillin). Other lectures discuss the diagnosis of allergic diseases and delimitation of their occupational aspects, some consideration of the mechanism of sensitization, therapy, prevention, and compensation. A useful contribution from Dr. D. A. Williams evaluates statistically the "social consequences" of asthma, urticaria, other allergic disorders, eczema, and dermatitis; this work is based on the reports of our Ministry of Pensions and National Insurance, and it is probably true to say that comparable information hardly exists for other parts of the world.

The merits of this book grow out of its broad scope, its widely European authorship, and the speed of publication. Its weaknesses mainly stem from the same origins. The lectures are uneven in quality and include much that is already well known. They overlap considerably, and some contain large numbers of spelling mistakes and printers' errors. Some include details of the author's place of work and country of origin, others leave the reader to guess. Some give properly set out lists of references, others mention authors (with dates) in the text, but give no other help to those who would like to consult the original source. The chapters which stand out as specially good concern nasal affections as occupational diseases and occupational sensitization of the air passages by organic dust; there are also stimulating discussions of turpentine and of the dyes used in cotton printing.

\section{J. R. SQUIRE}

Noise and Your Ear: Modern Monographs in Industrial Medicine. 1. By Aram Glorig, Jr. (Pp. viii + 152; illustrated. 46s.) New York and London: Grune \& Stratton. 1958.

Acoustics, Noise, aud Buildings. By P. H. Parkin and W. R. Humphreys. (Pp. 331 ; illustrated. 70s.) London: Faber and Faber. 1958.

Here are two recent additions to the current flood tide of literature concerning noise. They arrive at a time when British industry and industrial physicians are taking a much closer interest in this particular aspect of the physical environment, and at a time when for many of us life is on the verge of becoming even noisier. Although each is written for a different public each, in its own way, is authoritative. 
Glorig's small but expensive monograph (over three shillings per page!) can immediately be assessed as well worth the cost. It is the first of a series of modern monographs in industrial medicine, the whole series to be edited by A. J. Lanza; future projects concern industrial rehabilitation, alcoholics at work, sight conservation, and the employment of cardiac patients. If these promised siblings all prove to be as readable and explicit as their "noisy" elder brother, Dr. Lanza will have fathered a family of notable distinction.

The monograph is written "primarily for persons who require only a general knowledge of the subject, persons who are interested in many biologic hazards of which noise exposure is only one, and persons who may find it their responsibility to organize noise control programmes and hearing conservation programmes".

The author writes with acknowledged authority. He is Director of Research, Sub-Committee on Noise in Industry of the Committee on Conservation of Hearing of the American Academy of Ophthalmology and Otolaryngology.

The book is divided into seven sections: Introduction; The Ear and Hearing; Audiometry; Hearing Loss; Effects of Noise Exposure; Conservation of Hearing; and Compensation and Rating Scales. This may not necessarily be a logical sequence but the text and the development of concepts flow smoothly.

The glossary of audiological terms in section $\mathbf{I . 3}$ is particularly useful. Herein the author emphasizes (p. 21) the importance of identifying the reference level whenever sound levels are quoted. This he himself assiduously does, except on p. 50, Fig. 5, 4, where the reference level of the ordinate expressed in decibels is omitted but understood to be 0.0002 dynes per square centimetre. This, however, is but a trivial omission.

In 9.5 (pp. 83 and 84) which deals with the proper care and calibration of audiometers, mention is not made of the British standard of calibration which differs significantly from its transatlantic counterpart. As the monograph is published both in New York and London this can be misleading for British readers. The somewhat parochial attitude in relation to statutory recognition of occupational hearing loss is surprising in a book presumably designed for international reference. Some 20 countries have specific legislation of this nature (Great Britain is not amongst them) and "blanket coverage" for all forms of ills occupationally arising is a feature of many lands. The question raised therefore is not carping by a "little englander": many large international consortia and transport organizations operate hazardously noisy processes in countries having an explicit legal remedy for locally employed nationals.

Some authorities in this country might not readily accept the author's estimate (p. 133) of noise-induced hearing loss in the industrial population, based on the 1954 Wisconsin State fair hearing survey; statistical objections, in part valid, can be postulated. The estimated possible cost of compensation in the United States during the next decade is quoted as 154 million dollars if the specific criteria pertaining in the State of Wisconsin are applied; such talk of Eldorado makes the humblest physician here feel quite heady!
The discussion of compensation and rating scales is particularly interesting for readers here; a great deal can be learned from such transatlantic experience.

"Acoustics Noise and Buildings" is produced by a scientist from the Building Research Station (Parkin) and a consultant architect (Humphreys), in a more simple and comprehensible manner than Harris", "Handbook of Noise Control" and it covers many aspects therein considered. The book will be of particular interest to the architect, the acoustics engineer, and all who are interested in achieving at the design stage, conditions likely to augment working efficiency. The main emphasis is on criteria of acoustic comfort rather than on safety for noise-induced hearing loss.

The chapters dealing with the nature of sound, behaviour of sound in rooms, sound insulation and noise control, and that on criteria for sound insulation and noise control, possess interest for readers of this journal. Appendix A contains a useful table of absorption coefficients of some 65 materials commonly used in sound insulation planning. Appendix D tables a baker's dozen of some everyday industrial noises analysed in octave bands. Few industrial physicians would need to have this book always to hand, but it is a valuable reference source when considering architectural plans for noisy sites, or for premises where the exacting and skilled nature of the job demands freedom from distracting sound.

OWEN MCGIRR

Recent Studies in Epidemiology. Edited by $\mathbf{J}$. Pemberton and H. Willard. (Pp. xiii + 203; illustrated. 25s.) Oxford: Blackwell Scientific Publications. 1958.

The 18 papers in this book were presented at the Study Group on Current Epidemiological Research organized by the International Corresponding Club and held in Holland in 1957. The aim, which has been realized, was to assemble information on the ways in which epidemiological methods are being used in different parts of the world to investigate the incidence and causation of disease and to assess the needs of communities for various health services. The main topics discussed and covered by the chapters of the book are: the use of existing morbidity and the mortality records in epidemiological research; the ad hoc field survey or getting your own data; the evaluation of health needs and services by the epidemiological method including applications to underdeveloped territories; application of the epidemiological method to problems in mental health; general practice as a field for epidemiology.

This is not a text-book of epidemiology; it goes further than a text-book in giving practical examples, carefully worked out by experts, of epidemiological techniques. These examples will be of great help to those who wish to brush up their epidemiology. Some, such as the studies of sickness absence records in chronic bronchitis (D. D. Reid), observer error (C. M. Fletcher), and cancer of the lung and cancer of the nose in nickel refiners (W. Richard Doll), are of direct interest in occupational health.

L. G. NORMAN 